\title{
Exploring Inbound Tourists Experience in Beijing, China: An Online Deductive Approach
}

\author{
Yu Liu, Bingjie Liu-Lastres, Qiuju Wang, Yao-Yi Fu
}

\begin{abstract}
Purpose

Beijing is becoming one of the top global destinations but the number of international tourists to the city has been declining recently. By analyzing inbound tourists experience in Beijing and identifying the relationship between the destination attributes and satisfaction, this study provides important insights into city tourism research and city destination development.

\section{Design/methodology/approach}

This study used an online deductive approach and collected 1254 reviews on TripAdvisor referencing major attractions in Beijing. This study used the Leximancer software to analyze the content of the reviews and to identify the underlying relationships.

\section{Findings}

The results showed that international tourists' experience in Beijing can be reflected via five aspects: Attractions, City, Transportation, Service and People. The results further indicated that the major concern of international tourists visiting Beijing related to the service quality on site.

\section{Originality/value}

This study explored inbound tourists experience in Beijing using an online deductive approach. Practical implications were provided with respect to improving international tourists experience in Beijing and enhancing their satisfaction and revisiting intentions.
\end{abstract}

This is the author's manuscript of the article published in final edited form as:

Liu, Y., Liu-Lastres, B., Wang, Q., \& Fu, Y.-Y. (2019). Exploring inbound tourists experience in Beijing, China: An online deductive approach. International Journal of Tourism Cities. https://doi.org/10.1108/IJTC-04-2018-0026 
Key Words: Destination Attribute, Tourist Experience, Beijing, Inbound Tourists, Social MediaINTRODUCTION

Beijing is an iconic city of China and has become one of the largest city destinations around the globe (WTTC 2018). The development of the tourism industry has benefited from hosting the 2008 Summer Olympic Games, which has added new infrastructures, generated a welcoming attitude among local residents, and facilitated the city's transformation towards an urban destination characterized by "fashion and vitality" (Singh and Zhou 2016). In 2017, the tourism and travel industry has contributed $7.5 \%$ of the city's GDP, with a $12 \%$ share of revenue from international spending (WTTC 2018). However, the pace of tourism development in Beijing has been slowing down recently, which is partly due to more limited government-related business travel as well as the declining number of international visitors (WTTC 2017). Accordingly, the city government and the local DMO has undertaken multiple measures (e.g., Beijing Gift Program) to encourage inbound tourism and to attract more international tourists (Xinhua News Agency 2017).

The key to enhance destination competitiveness is to understand the importance and impacts of destination attributes (Crouch 2011). Several studies (e.g., Crouch and Ritchie 1999; Crouch 2011; Lew 1987; Kim 2014) reported that destination attributes significantly affect the formation of destination images and how people selecting a place to visit. Crouch and Ritchie (1999) developed a comprehensive model for examining destination attributes; this model was expanded later to include 36 destination attributes that could affect a destinations' competitiveness (Crouch, 2011). These statements suggest that attributes are critical for promoting a destination. However, it is noted that the characteristics of each destination may vary (Kim 2014). Also, due to cultural factors, international tourists and domestic tourists are 
likely to perceive and evaluate destinations differently (Eusébio and Vieira 2013). For instance, Feng (2011) found that although both domestic and international tourists were attracted to the heritage/culture features of Beijing, domestic tourists especially appreciated the political symbolic feature of Beijing, while international visitors preferred the natural environment of Beijing. In the same vein, an early research Gibson et al. 2008) showed that attributes such as scenery, cultural and heritage attractions, local people, and exotic cuisine are major motivators attracting international tourists to visit Beijing. Likewise, Xie and Lee (2013) found that elements such as the natural environment, built environment, and local people all serve as important attributes contributing to international travelers' positive impression of Beijing.

Furthermore, tourists' evaluation of destination attributes influences their tourist experience as well as satisfaction, as Eusébio and Vieira (2013) suggest that tourist satisfaction should be examined as a function of attribute-level evaluations. Tourist satisfaction is critical for destination marketing because it can significantly influence visitors' intentions to recommend and return. Traditionally, the relationship between destination attributes and tourist satisfaction is measured through field studies (e.g., survey); while in recent years, with the rapid development of information technology, a growing number of studies have used online travel reviews as the primary data to examine tourists experience, evaluation of destination attributes, as well as satisfaction (Kladou and Marvagani 2015; Pan and Li 2011; Tseng et al. 2015). These online reviews are considered authentic, genuine, and unbiased, therefore, they are more likely to generate greater impact on other tourists' perceptions and decisions (Pan and Li 2011).

Given that Beijing is building a new global brand image and it has been nearly ten years since the 2008 Beijing Olympic Summer Game, it is imperative to understand inbound tourists' evaluation of the destination attributes of Beijing as well as the relationship between the 
destination attributes and tourist satisfaction among this population. Thus, using an online deductive approach, this study analyzed inbound tourists' online reviews referencing major attractions in Beijing and tried to answer the following research questions:

1. What are the major destination attributes of Beijing as reflected in inbound tourists' online reviews?

2. Are there any associations between the destination attributes and the level of tourist satisfaction?

\section{METHODS}

\section{Data Collection}

Tourist attractions in China are rated by the Chinese authorities to determine their quality relative to its peers in terms of cleanliness, sanity, transportation and safety. The rating system covers five categories ranging from $1 \mathrm{~A}$ (the lowest level) to $5 \mathrm{~A}$ (the highest level). There are seven 5A tourist attractions in Beijing: (1) the Forbidden Palace museum, (2) Temple of Heaven, (3) Summer Palace, (4) Badaling-Mutianyu (Great Wall), (5) Ming tombs, (6) Prince Gong Mansion (Gong Wangfu) and (7) the Olympic Green. These 5A attractions not only represent the best quality of tourism products in China, but also attract most international tourists' attention.

Given the importance of the 5A attractions, this study collected all the user-generated content on TripAdvisor that reviewed these seven attractions in between June 19, 2013, to June 19, 2015. The main subjects are English-speaking inbound tourists. A total of 1254 reviews were collected, along with its rating of the overall visiting experience. After filtering out non-English reviews, a total of 1054 online reviews were included in the analysis. Each review represents one visit to the attraction. 


\section{Data Analysis}

The data analysis process was completed by the Leximancer software, which is becoming a popular tool for textual analysis and has been used in several tourism studies (e.g., Chiu and Leng, 2017; Li and Pearce, 2016). Based on the calculation of word frequencies and cooccurrences, Leximancer is able to generate a structural word-concept-theme framework that can represent the meanings of the data as well as illustrate the relationships between key themes/concepts (Smith, 2003). The specific data analysis was complete via three steps. Firstly, based on the results of the preliminary tests, antonyms and synonyms were merged in the subsequent analysis (i.e., "like" and "likes" were merged into one word). Secondly, through an automated coding process, Leximancer generated concept maps that summarize the major focus of the reviews in the sample. The strengths of the relationships among key concepts/themes are examined in terms of connectivity probability rate, which ranges from 0 (no relations) to 1 (the probably of these two themes occurring at the same time is $100 \%$ ). Thirdly, to explore the factors that may influence tourists' satisfaction, the relationships between themes/concepts among reviews of different ratings were also tested. Each review serves as a unit of analysis and one review may contain multiple themes.

\section{RESULTS AND DISCUSSION}

\section{Major Destination Attributes of Beijing}

The average length of the review was 80 words long. The results of Leximancer analysis showed the major attributes of Beijing can be reflected via the following five themes, which were color-coded and presented in Fig 1: (1) Attractions (red) (n=1054,100\%), (2) City (yellow) 
$(\mathrm{n}=865,84.5 \%)$, (3) Transportation (purple) (n-752, 71.3\%), (4) Service (light green)

$(\mathrm{n}=625,59.3 \%)$, and (5) People (dark green) $(\mathrm{n}=552,52.4 \%)$. A total of 62 sub-themes were generated, which were linked to different concepts (Figure 1). Particularly, the gray nodes in Figure 1 represent the associations among different concepts and the red lines indicate the relationships between the themes and sub-themes.

[Insert Figure 1 Here]

Attractions is considered the most significant attribute among international tourists' travel experience in Beijing. This is expected as all the reviews in the sample are directly related to major attraction in Beijing. Given the central role play be Attractions within the thematic analysis, a further test was conducted to explore the relationships between Attractions and other concepts. As shown in Table 1, the theme Attractions was strongly related to several sub-themes (concepts), such as palace, garden, buildings, and great wall. Such foci on places are not surprising, as all the reviews were supposed to be surrounding attractions and international tourists have the tendency to document their specific activities at destinations (Pan and Li 2011; Tseng et al. 2015). Additionally, the results here align well with previous findings (e.g., Gibson et al. 2008; Xie and Lee 2013), which pointed out that elements such as natural scenery, the built averment, and the exotic atmosphere all play a significant role in determining how tourists perceive and define attractions.

\section{[Insert Table 1 Here]}

City and People are another two important themes that emerged from the sample. The concentration on City is expected as it is the major focus of this study. Beijing is the capital city of China and is normally perceived as the political and cultural center. Naturally, international 
tourists tend to depict their travel experience to China via their interactions with the city. The public service and the infrastructure provided by the city not only facilitate people's travel activities and but also can be incorporated as part of travel experiences (Judd and Feistein 1999). People is another theme extracted from the sample. People is a very broad concept and covers multiple types of individuals, including local residents, employers that work in the tourism and hospitality industry, and other tourists. Notably, the interaction with diverse people can lead to distinctive reactions. For example, one tourist shared his/her interaction with the local people with great excitement - "Beijing locals use this park quite heavily for their own recreational needs, it is very fun that there are a great many people exercising Tai Chi and children playing amidst the trees." While another tourist expressed his/her concerns of crowdedness at a tourist spot --“There are many gates to enter inner palace area. Superb crowded with local and foreign tourists."

Service and Transportation also represent inbound tourists' experience in Beijing. This concentration, interestingly, is consistent with the findings of Zhang and Zhao's study (2009) which examined the long-term effect of Olympic Games on Beijing and found that areas such as quality of tourist service and the transportation system need further improvement. Service quality in the attraction appears to be one of the major foci of the reviews in the sample, and the most discussed aspects include tickets, souvenir, and food. The results here align well with the nature of tourism and hospitality service and confirm that international tourists' perception of service is comprehensive and possess a scope beyond simply sight-seeing. In addition to the service, transportation is also frequently reported in the sample. Interestingly, these international tourists were paying special attention to the transportation within the attraction, such as cable/lift, shuttle/bus, and the boat. It seems that they regarded the transportation experience as an 
important component of their overall travel experience. For example, one tourist shared his/her experience with the lift in the review, commenting that "In June, we took the chair lift up and had great views, then took the luge sled ride down, which was a lot of fun for all of us, especially our teenagers."

\section{Satisfaction or Dissatisfaction?}

This study also attempted to identify the major attributes that may lead to one's satisfaction/dissatisfaction with their travel experiences. To achieve the goal, this study repeated the conceptual map analysis with two additional factors, which is (1) the rating of the review, and (2) the specific tourist attraction. As showed in Figure 2, four themes were generated: (1) Attraction, (2) Transportation, (3) Service, and (4) Chinese, which covered the old themes City and People. Red tags represent the newly added elements (i.e., rating and tourist attraction), and a closer distance between a concept/theme and a tag represents a closer relationship between these two factors.

\section{[Insert Figure 2 Here]}

The results indicated that the attractions that tend to receive higher ratings are (1) the Great Wall, (2) the Summer Palace, (3) the Temple of Heaven, and (4) the Olympic Greens. The most prevalent themes associated with these attractions were Chinese, Attraction, and Transportation. Interestingly, although Olympic Green receives a higher rating among the attractions, it seems that most prominent themes emerged from these reviews still surround heritage resources. As one review explicated, "Spectacular! The palace and its grounds are lovely, lots of beautiful buildings, gardens, walkways, artifacts, and of course the lake!" Meanwhile, the results showed that the following attractions were more likely to receive a lower 
rating: (1) the Ming tombs, (2) the Prince Gong Mansion (Gongwangfu), and (3) the Forbidden City Museum.

Given the central role played by Service in attraction management, tourist experience, and guest satisfaction, a further test was performed to assess the probability of occurrence of Service-related sub-themes among reviews of different ratings. As shown in Table 2, the subthemes (concepts) of Ticket, Souvenir, Tour Guide and RMB are more likely to be associated with positive reviews that have a rating of 4 or 5 . It is noted that the sub-theme (concept) Scam is associated with low-rating reviews. This is a type of negative experience that shared by both domestic and international tourists (Li and Pearce 2016). As one review explained, "the scams could happen from the tri-motorcycle drivers. They think you are a rich guy which they can get some more easy money: they bring you to a 'guided tour' company, you pay RMB 70 for the RMB40 plus their guide service."

[Insert Table 2 Here]

\section{CONCLUSIONS}

The purpose of this study was to identify the major destination attributes of Beijing in the eyes of inbound tourists via online travel reviews. The primary results suggest five major themes of destination attributes, namely, attraction, city, people, service, and transportation. These themes are largely consistent with previous findings (Gibson et al. 2008; Xie and Lee 2015). The results suggest that international tourists' perception of attractions is comprehensive, and they are more likely to be attracted to the historical and cultural features of the attractions in Beijing. In addition to the consistencies with the existing literature, the findings of this study are able to provide in-depth insights. For example, the interpretation of the People theme has moved beyond the traditional scope from focusing on local residents only to incorporate a wider variety of 
populations, such as tourism and hospitality workers and other travelers. Likewise, the interpretation of the Service theme appears to be two-fold: on one hand, travelers were satisfied with the value of the ticket, the souvenir, and the tour at the attraction; on the other hand, they were frustrated with tourist scams (Li and Pearce 2016).

Unlike other forms of tourism (e.g., rural, mountain, etc.), city tourism research requires an adequate understanding of the urban context, the interactions between travelers and the city, as well as the relationships between city and tourism development (Ashworth and Page 2011). The findings of this study lend support to such argument, as it is noted that even though all the reviews in the sample were concerned about 5A attractions and various elements of the city (e.g., infrastructure, transportation, people) have also been featured. Thus, a holistic approach is needed in future studies, which not merely consider tourism product development, but also take into account important concepts such as satisfaction, place marketing, and urban development. Another interesting finding noted in this study relates to the interpretation of the themes. Previous studies tend to outline the main categories that can represent destination attributes, while the findings of this study noted that an in-depth exploration is necessary to fully illustrate the meaning of these categories. This is reflected in the abovementioned discussion related to the themes People and Service. Therefore, future studies should bear this in mind and explore the actual impacts of the specific dimensions within a broad category.

Practically speaking, the findings of this study also provide several implications for attraction/city managers and planners. Firstly, to remove international tourists' concerns, future endeavors should be devoted to improving the service quality at tourist spots and feature the historical and cultural features of attractions. Secondly, the officials need to monitor and regulate the service providers at the tourist site and avoid negative incidents like the scam. Lastly, given 
the important influence of eWOM, local DMOs should also devote efforts in creating a positive presence of Beijing as a contemporary city destination online.

This study has several limitations. This study only analyzed reviews that were written in English and published on TripAdvisor. This may limit the breadth of the findings. Future research can expand beyond these restrictions and analyze reviews of different languages and on different websites. Also, all the reviews included in this study were post-trip reviews, while a more comprehensive understanding of international tourists' perceptions and experience should incorporate opinions/viewpoints at different phases of travel, including pre-travel and during the travel. Furthermore, the software Leximancer was used in this study as the analytical tool, but there may be some limitations causing by the purely automated analysis process. Thus, it is recommended that future studies can combine Leximancer with some traditional analytical methods such as content analysis. Furthermore, the findings of this study are specific to Beijing and it may be difficult to replicate. The categories are general as well. However, it is expected that these findings can provide important insights as well as practical implications for related stakeholders. Lastly, sometimes travelers may express both positive and negative experience in their reviews, while this study may not be fully capture them since the interpretation of guest satisfactory largely depends on the review ratings. Advanced sentimental analyses are needed to overcome such limitations in future studies. 


\section{REFERENCES}

Ashworth, G. and Page, S.J., 2011. Urban tourism research: Recent progress and current paradoxes. Tourism management, 32(1), pp.1-15.

Chen, C.F. and Chen, F.S., 2010. Experience quality, perceived value, satisfaction and behavioral intentions for heritage tourists. Tourism management, 31(1), pp.29-35.

Crouch, G.I. and Ritchie, J.B., 1999. Tourism, competitiveness, and societal prosperity. Journal of business research, 44(3), pp.137-152.

Chiu, W. and Leng, H.K., 2017. Let's go cycling: an analysis of tourists' experience on online user-generated content. International Journal of Tourism Cities, 3(1), pp.30-42.

Eusébio, C. and Vieira, A.L., 2013. Destination attributes' evaluation, satisfaction and behavioural intentions: A structural modelling approach. International Journal of Tourism Research, 15(1), pp.66-80.

Feng, J. 2011. Perceptions of the Image of Beijing's Tourist Destinations-An Analysis of the Multi-dimensional Discourses on the Blogs from Chinese and Western Tourists. Tourism Tribune, 26(9), pp. 19-28.

Gibson, H.J., Qi, C.X. and Zhang, J.J., 2008. Destination image and intent to visit China and the 2008 Beijing Olympic Games. Journal of Sport Management, 22(4), pp.427-450.

Judd, D.R. and Fainstein, S.S. eds., 1999. The tourist city. Yale University Press.

Kim, J.H., 2014. The antecedents of memorable tourism experiences: The development of a scale to measure the destination attributes associated with memorable experiences. Tourism management, 44, pp.34-45.

Kladou, S. and Mavragani, E., 2015. Assessing destination image: An online marketing approach and the case of TripAdvisor. Journal of Destination Marketing \& Management, 4(3), pp.187-193.

Lew, A.A., 1987. A framework of tourist attraction research. Annals of tourism research, 14(4), pp.553-575.

Li, X. and Wang, Y., 2011. China in the eyes of western travelers as represented in travel blogs. Journal of Travel \& Tourism Marketing, 28(7), pp.689-719.

Li, J. and Pearce, P., 2016. Tourist scams in the city: challenges for domestic travellers in urban China. International Journal of Tourism Cities, 2(4), pp.294-308.

Pan, B. and Li, X.R., 2011. The long tail of destination image and online marketing. Annals of Tourism Research, 38(1), pp.132-152. 
Singh, N. and Zhou, H., 2016. Transformation of tourism in Beijing after the 2008 Summer Olympics: An analysis of the impacts in 2014. International Journal of Tourism Research, 18(4), pp.277-285.

Smith, A.E., 2003, May. Automatic extraction of semantic networks from text using Leximancer. In Proceedings of the 2003 Conference of the North American Chapter of the Association for Computational Linguistics on Human Language Technology: Demonstrations-Volume 4 (pp. 2324). Association for Computational Linguistics.

Tseng, C., Wu, B., Morrison, A.M., Zhang, J. and Chen, Y.C., 2015. Travel blogs on China as a destination image formation agent: A qualitative analysis using Leximancer. Tourism Management, 46, pp.347-358.

Tung, V.W.S. and Ritchie, J.B., 2011. Exploring the essence of memorable tourism experiences. Annals of tourism research, 38(4), pp.1367-1386.

WTTC 2017. Beijing City Travel and Tourism Impact. Available from https://zh.wttc.org/

Xie, K. L. \& Lee, J.-S. (2013) Toward the perspective of cognitive destination image and destination personality: The case of Beijing, Journal of Travel \& Tourism Marketing, 30(6), pp. 538-556.

Xinhua News Agency. 2017.Beijing Receives 285 billion visitors. Available from http://www.xinhuanet.com

Zhang, L. and Zhao, S.X., 2009. City branding and the Olympic effect: A case study of Beijing. Cities, 26(5), pp.245-254. 